\title{
MAGNETIC RESONANCE IMAGING FOR DIAGNOSING THE PRE-SLIP STAGE OF THE CONTRALATERAL PROXIMAL FEMORAL EPIPHYSIS IN PATIENTS WITH UNILATERAL EPIPHYSIOLYSIS
}

Nei Botter Montenegro', Victor Fruges Junior ${ }^{2}$, Riccardo Grinfeld $^{2}$, Marcelo Bordalo Rodrigues $^{3}$, Edgard dos Santos Pereira ${ }^{4}$, Carlos Gorios ${ }^{5}$

\section{ABSTRACT}

Objective: To assess the importance of using conventional magnetic resonance imaging and $\mathrm{T} 2$ mapping to determine the pre-slip stage of the contralateral epiphysis in patients with a clinical and radiographic diagnosis of unilateral proximal femoral epiphysiolysis who were initially treated with in-situ fixation. Methods: This prospective clinical study on 11 patients with unilateral epiphysiolysis was conducted between February 2009 and August 2010, using magnetic resonance imaging on the contralateral hip. Results: We observed abnormalities in the proximal femoral capital physis of the contralateral unaffected hip, with edema under the growth plate in $27 \%$ of the patients assessed. Conclusion: Magnetic resonance imaging is an early and sensitive method for detecting the pre-slip stage of the proximal femoral epiphysis.

Keywords - Epiphysis, Slipped; Magnetic Resonance Imaging; Diagnosis

\section{INTRODUCTION}

Proximal femoral epiphysiolysis is characterized by anterosuperior displacement of the femoral neck in relation to the capital epiphysis, in the hypertrophic layer of the growth plate. It is also known as adolescent coxa vara ${ }^{(1)}$.

Its prevalence varies depending on the ethnic region studied. On average, it occurs in two adolescents per 100,000 individuals $^{(2)}$ It is most common between the ages of 10 and 16 years, in males (male-female ratio of $1.43: 1)$, predominantly on the left side (2:1) and among blacks. Patients with epiphysiolysis can be grouped into two biotypes: Frolich (adipose genital type) and, in a smaller proportion, Mikulicz (tall and thin type). Symptomatic bilateral involvement may occur at rates between 9 and $25 \%$, according to the literature ${ }^{(3-5)}$. However, after months of follow-up, this incidence may increase $^{(3,4)}$, with bilateral involvement appearing in 60 to $80 \%$ within 18 months after the first slippage ${ }^{(1)}$.

The objective of this prospective study was to assess the importance of using conventional magnetic resonance imaging and T2 mapping to determine the diagnosis of the pre-slip stage in the contralateral epiphysis, in patients with a clinical and radiographic diagnosis of unilateral proximal femoral epiphysiolysis who were initially treated with in-situ fixation.

\section{MATERIAL}

This sample for this prospective clinical study conducted between February 2009 and August 2010 was

1 - PhD. Physician and Professor in the Discipline of Pediatric Orthopedics, Hospital das Clínicas, School of Medicine, University of São Paulo, São Paulo, Brazil.

2 - Resident Physician in Orthopedics and Traumatology, Orthopedics and Traumatology Service, University of Santo Amaro (UNISA), São Paulo, Brazil.

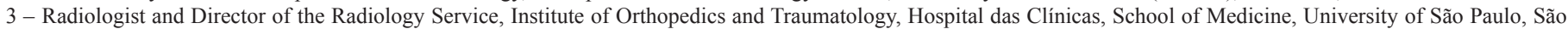
Paulo, Brazil.

4 - Physician and Titular Professor of the Discipline of Orthopedics and Traumatology, University of Santo Amaro (UNISA), São Paulo, Brazil.

5 - Physician and Coordinator of Residence in Orthopedics and Traumatology, University of Santo Amaro (UNISA), São Paulo, Brazil.

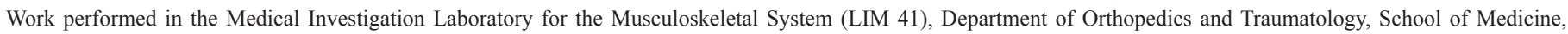
University of São Paulo.

Correspondence: Rua Dr. Ovídio Pires de Campos, 333, Térreo - 05403-010 - São Paulo, SP - E-mail: neibotter@einstein.br

Work received for publication: September 20, 2010; accepted for publication: September 29, 2010.

The authors declare that there was no conflict of interest in conducting this work 
composed of 11 patients with signs and symptoms suggestive of unilateral epiphysiolysis. The diagnosis was confirmed using radiographic examinations in anteroposterior and Lauenstein views. There were six male patients and five female patients, of ages between nine and fifteen years, who were operated with in-situ fixation. Four other individuals without clinical or radiographic signs or symptoms of the disease formed a control group (eight hips). Patients with radiographic signs of bilateral epiphysiolysis (seen previously on magnetic resonance imaging), endocrine disease or renal osteodystrophy were excluded from this study. The patients were treated at the Orthopedics and Traumatology Service of the University of Santo Amaro (Tables 1 and 2).

Table 1 - Patients treated for unilateral proximal femoral epiphysiolysis, according to sex, age, side affected, grade of slippage (Bianco method), date of surgery and date of magnetic resonance imaging.

\begin{tabular}{c|c|c|c|c|c}
\hline Patient & Sex & Age & Side & Grade & Date of Surgery \\
\hline 1 & M & 9 & E & I & 22.02 .2009 \\
\hline 2 & F & 11 & E & I & 27.08 .2009 \\
\hline 3 & M & 15 & E & I & 15.10 .2009 \\
\hline 4 & M & 11 & E & II & 15.11 .2009 \\
\hline 5 & F & 12 & D & I & 16.11 .2009 \\
\hline 6 & M & 13 & E & I & 18.11 .2009 \\
\hline 7 & M & 12 & E & I & 14.12 .2009 \\
\hline 8 & M & 14 & E & I & 18.02 .2010 \\
\hline 9 & F & 13 & D & I & 10.03 .2010 \\
\hline 10 & F & 11 & E & I & 02.07 .2010 \\
\hline 11 & F & 12 & E & II & 19.08 .2010 \\
\hline L - left side; R - right side. &
\end{tabular}

Table 2 - Control group patients.

\begin{tabular}{c|c|c}
\hline Patient & Sex & Age \\
\hline 12 & $\mathrm{M}$ & 13 \\
\hline 13 & $\mathrm{M}$ & 12 \\
\hline 14 & $\mathrm{M}$ & 11 \\
\hline 15 & $\mathrm{M}$ & 11 \\
\hline
\end{tabular}

\section{METHODS}

With the aim of investigating the possibility of pre-slip in the hip contralateral to the operated side, magnetic resonance imaging examinations were performed at the Radiology Service of the Institute of Orthopedics and Traumatology, Hospital das Clinicas, School of Medicine, University of São Paulo.
All the magnetic resonance examinations were performed in a magnet of 1.5 Tesla (HDXT, General Electric Medical Systems, Milwaukee, Wisconsin, United States) using a surface spool (Medrad, Indianola, PA, United States). All the hips were maintained in the neutral position, with the patient in dorsal decubitus. Images were produced in the axial, sagittal and coronal planes. The sequences used were: axial T2 with fat saturation (TR/TE: 3,500-4,400/55-65), axial T1 (400-600/10-16), sagittal T2 with fat saturation $(3,500-$ 4,600/55-65), sagittal T1 (400-650/10-16) and coronal T2 with fat saturation (3,500-4,200/52-65). Multi-echo sequences for producing T2 maps of the growth plate were also performed. Coronal T2 maps were obtained from multi-spin echo sequences (TR, 1,500; eight echoes spaced between 10 and 90 milliseconds).

\section{RESULTS}

Clinically, 10 patients presented the Frolich biotype (adipose genital) and one had the Mikulicz type, without associated endocrine diseases.

The imaging findings from the magnetic resonance examinations on the hips contralateral to the treated hips are represented in Table 3. Eight hips from eight asymptomatic individuals were also analyzed, without findings of abnormalities on conventional magnetic resonance imaging (Table 4). These examinations were taken to be the standard for assessing the contralateral hips of the patients with epiphysiolysis (Figure 1).

We found abnormalities in the proximal femoral

Table 3 - Patients studied and respective imaging findings from magnetic resonance examinations on the hips contralateral to the hips treated for epiphysiolysis.

\begin{tabular}{c|c|c|c|c}
\hline Patient & Side & Pain & $\begin{array}{c}\text { Focal Edema } \\
\text { On MRI }\end{array}$ & $\begin{array}{c}\text { Diffuse Edema } \\
\text { On MRI }\end{array}$ \\
\hline 1 & R & No & No & No \\
\hline 2 & R & No & Yes & Yes \\
\hline 3 & R & No & Yes & Yes \\
\hline 4 & R & No & No & No \\
\hline 5 & L & No & No & No \\
\hline 6 & R & No & No & No \\
\hline 7 & R & No & No & No \\
\hline 8 & $R$ & No & No & No \\
\hline 9 & L & No & No & No \\
\hline 10 & R & No & No & No \\
\hline 11 & R & No & Yes & Yes \\
\hline
\end{tabular}

MRI - magnetic resonance imaging; $\mathrm{L}$ - left side; $\mathrm{R}$ - right side. 
capital growth plate region on the side contralateral to the disease, with edema under the growth plate in $27 \%$ of the patients analyzed (Figures 2 and 3 ).

After the magnetic resonance examinations, during the outpatient follow-up, two patients presented pain in the contralateral hip on walking, but no radiographic signs of pre-slip or epiphysiolysis were found in these patients.

Table 4 - Study on control group individuals: magnetic resonance examinations on right and left hips.

\begin{tabular}{c|c|c|c|c}
\hline Patient & Side & Pain & $\begin{array}{c}\text { Focal edema on } \\
\text { MRI }\end{array}$ & $\begin{array}{c}\text { Diffuse edema on } \\
\text { MRI }\end{array}$ \\
\hline 12 & R/L & No & No & No \\
\hline 13 & R/L & No & No & No \\
\hline 14 & R/L & No & No & No \\
\hline 15 & R/L & No & No & No \\
\hline
\end{tabular}

L- left side; $\mathrm{R}$ - right side.

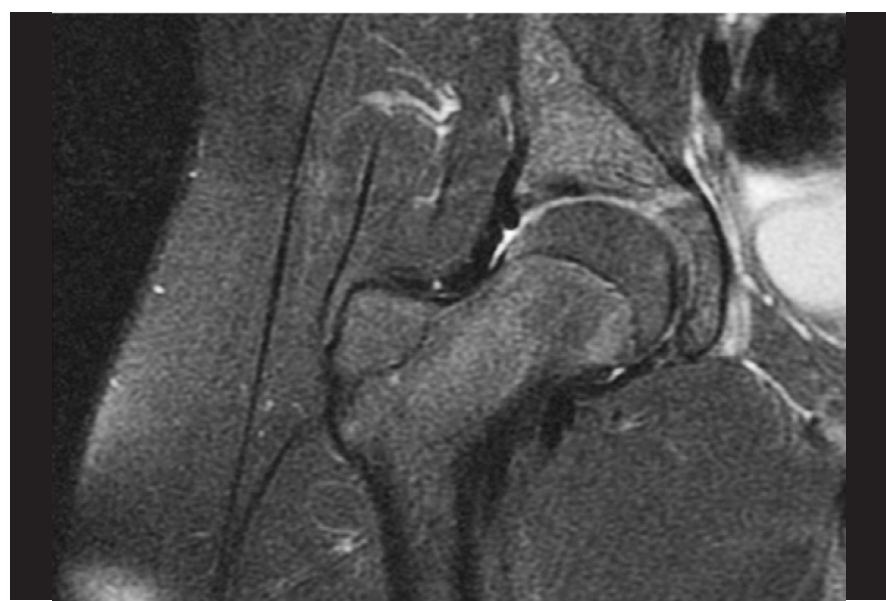

Figure 1 - Normal hip. T2-weighted coronal image with fat saturation on the right hip of an asymptomatic 11-year-old boy.

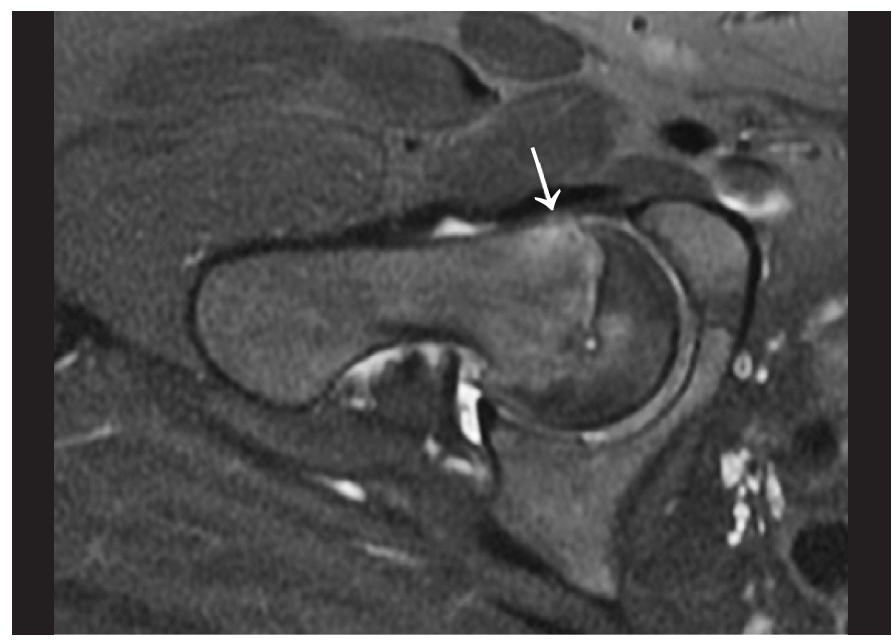

Figure 2 - T2-weighted axial image with fat saturation on the right hip showing edema in the metaphysis and growth plate, with slight epiphyseal focal misalignment (arrow).

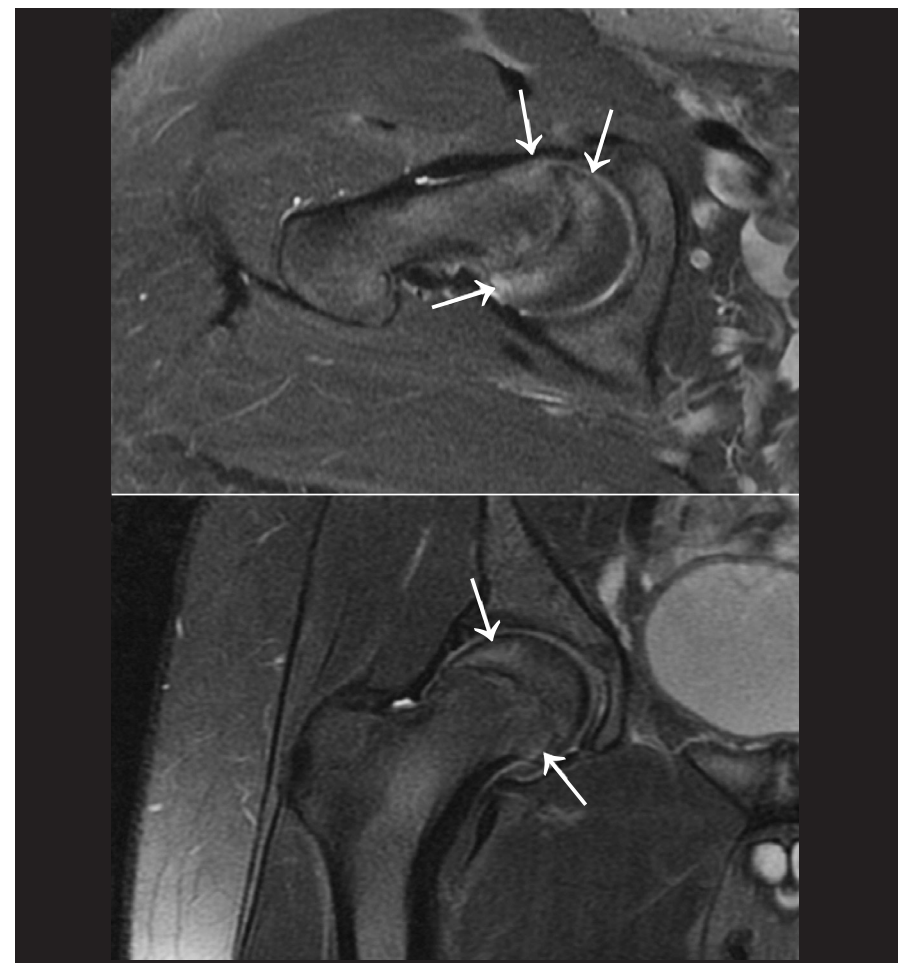

Figure 3 - T2-weighted axial $(\mathrm{A})$ and coronal $(\mathrm{B})$ images with fat saturation on the right hip showing diffuse edema around the growth plate, which also presents slight edema (arrows).

\section{DISCUSSION}

The most serious early complications from epiphysiolysis are chondrolysis and avascular necrosis of the femoral head. The first of these may occur during the natural evolution of the disease, or as a result of the treatment used. The second of these is closely related to certain procedures during the treatment, such as untimely in-situ reduction or fixation maneuvers in the posterior superolateral quadrant of the epiphysis ${ }^{(6)}$. The most feared late complication is early osteoarthrosis of the hip.

The rates of bilaterality reported in the literature have ranged from 9 to $25 \%$ according to the methodology used, with occurrences in 60 to $80 \%$ within 18 months after the first slippage. These numbers are a cause for concern, since the great majority of contralateral slippages occur without symptoms and the diagnosis is made in adulthood, in the form of degenerative disease ${ }^{(7)}$

In a study on in-situ fixation of the diseased hip, Simbalista Neto et $\mathrm{al}^{(8)}$ observed that in cases of pre-slip and grades I and II slippage, $100 \%$ of the results were good or excellent. On the other hand, in cases of excessive epiphyseal slippage, poor results could be 
attributed to poor positioning of the implant, which could lead to necrosis, chondrolysis and non-closure of the growth plate. Along this line of thinking, prophylactic fixation of the contralateral hip would keep this better positioned, thereby preventing the possibility of arthrosis.

Crawford $^{(2)}$ and Ferreira ${ }^{(9)}$ concluded in their studies that the possible complications from prophylactic fixation (chondrolysis and avascular necrosis) outweighed the benefits. Hence, they reserved this procedure for cases with hormonal disease and patients who were not in a socioeconomic condition conducive to good follow-up.

Laredo Filho et al $^{(4)}$ indicated contralateral in-situ fixation for at-risk hips (endocrine disease, female sex and black race), and also for patients of low socioeconomic condition who did not maintain outpatient follow-up.

Jerre et $\mathrm{al}^{(10)}$ recommended prophylactic fixation when there were radiographic signs of pre-slip, endocrine disease or recognized metabolic abnormalities, and typical biotypes with a propensity and high potential for residual growth.

Nelson Elias et $\mathrm{al}^{(7)}$ performed prophylactic fixation of the contralateral hip because they believed that this was a bilateral disease and that the risks of slippage, whether diagnosed or not, outweighed the risks of a procedure on the non-slipped side.

Based on a large number of successful cases of in-situ prophylactic fixation, with low morbidity, Santili ${ }^{(6)}$ recommended this procedure for girls under the age of 12 years and boys under the age of 14 years, as well as for individuals with endocrine diseases or recognized metabolic abnormalities, at any age.

Emery et $\mathrm{al}^{(11)}$ indicated prophylactic fixation in all cases, in view of the high rates of contralateral slippage and late osteoarthrosis.

Umans et $\mathrm{al}^{(12)}$ studied 13 patients, among whom 15 hips were symptomatic, with the aim of detecting early lesions through evaluations using radiography, computed tomography and magnetic resonance imaging. They reached the conclusion that the last of these methods was the most sensitive for early diagnosis, since it showed focal and diffuse edema in the epiphyseal region. The authors did not report using these methods for prophylactic detection of the disease in the contralateral hips, except in two cases that were already symptomatic.

In the literature, conventional magnetic resonance imaging has been used for early detection of epiphysiolysis. The so-called T2 mapping technique is a new and recently developed method for analyzing cartilage, and this is being introduced into medical practice for joint cartilage analyses. With the aim of achieving early detection of the disease in the contralateral hips of the patients in our sample, we performed both conventional and T2 mapping magnetic resonance imaging. All the examinations were evaluated by the same radiologist, a specialist in musculoskeletal analysis. The following parameters were taken into consideration: focal edema around the growth plate, diffuse edema under the growth plate and misalignment/epiphyseal slippage in relation to the metaphysis. We found signs of pre-slip (focal and diffuse edema) in three of the eleven patients that had not been seen on simple radiographs. After performing this last imaging examination, we performed clinical analysis on the patients and observed that two of the three patients with abnormalities on magnetic resonance imaging presented complaints of pain in the contralateral hip. This showed the capacity of this method for early diagnosis in relation to symptoms. The T2 mapping study was assessed through calculating the T2 time, but in all cases the thinness of the growth plate cartilage meant that no adequate calculation for analyzing the alterations in this tissue through T2 mapping was possible.

We agree with the authors who indicated prophylactic fixation of the non-slipped hip for patients with gigantism, hypogonadism, hypothyroidism and hyperparathyroidism (endocrine diseases), renal osteodystrophy and high growth potential ${ }^{(6)}$. We disagree with Crawford ${ }^{(2)}$ and Ferreira ${ }^{(9)}$ regarding the lack of benefit from contralateral fixation for patients without endocrine disease, given that patients who were not in the high-risk groups listed also presented the possibility that bilateral disease could occur.

As demonstrated in the present study, the magnetic resonance findings had high sensitivity for the diagnosis of pre-slip, which was shown earlier than either the clinical symptoms or the abnormalities detectable on radiographic examinations. Thus, we recommend that conventional magnetic resonance imaging should be 
done to show the possible growth plate abnormalities in the contralateral hip, in patients who have not been operated prophylactically.

Although this examination is not available in many medical centers and has a high cost, we believe that it would be prudent to perform it in order to prevent future deformities in the contralateral hip.

Prospective clinical studies with a larger case se- ries might help to define the best strategy for when and how often to request magnetic resonance imaging for the contralateral hip.

\section{CONCLUSION}

Magnetic resonance imaging was shown to be an early and sensitive method for detecting the pre-slip stage of the proximal femoral epiphysis.

\section{REFERENCES}

1. Kehl DK. Deslizamento da epífise femoral capital. In: Morrissy RT, Weinstein SL. Lovell and Winter's pediatric orthopaedics. 5a. ed. Tradução de Lambrinides CD, Nascimento FG, Strong S. São Paulo: Manole; 2001. p.1087-124.

2. Crawford AH. Current concepts review slipped capital femoral epiphysis. J Bone Joint Surg Am. 1998;70(9):1422-7.

3. Hägglund G, Hansson LI, Ordeberg G, Sandström S. Bilaterality in slipped upper femoral epiphysis. J Bone Joint Surg Br. 1988;70(2):179-81.

4. Laredo Filho J, Braga Júnior MB, Ishida A, Botoletto A. Estudo crítico da indicação da pinagem preventiva do lado sadio na epifisiólise proximal do fêmur unilateral. Rev Bras Ortop. 1987;22(6):173-6.

5. Neto AK. Epifisiólise proximal do fêmur. In: Hebert S, Xavier R, Pardini Júnior AG, Barros Filho TE. Ortopedia e traumatologia: princípios e prática. 3a. ed. Porto Alegre: Artmed; 2003. p. 321-33.

6. Santili C. Epifisiólise. Rev Bras Ortop. 2001;36(3): 49-56.
7. Elias N, Simbalista Neto L, Jorge FVF, Tamanini A, Cerqueira F, Syllos A, Abreu AV. Epifisiólise proximal do fêmur. Rev Bras Ortop. 1999;34(5): 333-8.

8. Simbalista Neto L, Elias N, Cerqueira F, Vassimon F, Tamanini A, Syllos A. Epifisiólise proximal do fêmur: estudo da fixação "in situ" com um parafuso esponjosa AO 6,5mm. Rev Bras Ortop. 1998;33(10): 815-21.

9. Ferreira JCA. Considerações sobre o escorregamento epifisário do fêmur. Rev Bras Ortop. 1996; 31(10): 809-14.

10. Jerre R, Billing L, Hansson G, Wallin J. The contralateral hip in patients primarily treated for unilateral slipped upper femoral epiphysis. Long-term follow-up of 61 hips. J Bone Joint Surg Br. 1994;76(4):563-7.

11. Emery RJ, Todd RC, Dunn DM. Prophylactic pinning in slipped upper femoral epiphysis. Prevention of complications. J Bone Joint Surg Br. 1990;72(2):217-9.

12. Umans H, Liebling MS, Moy L, Haramati N, Macy NJ, Pritzker HA. Slipped capital femoral epiphysis: a physeal lesion diagnosed by MRI, with radiographic and CT correlation. Skeletal Radiol. 1998; 27(3):139-44. 